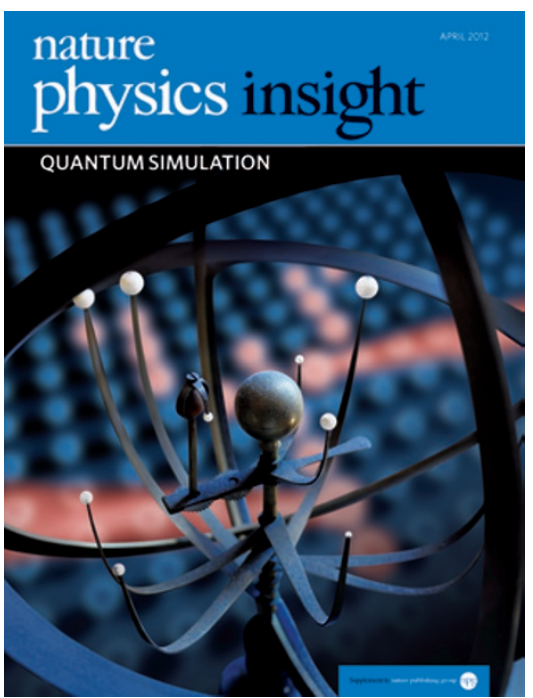

\section{COVER IMAGE}

Before the advent of digital computers, sophisticated orreries were used to predict the positions and motions of astronomical bodies. Now quantum simulators hold the promise of providing insight into the behaviour and properties of complex quantum systems, in situations where classical computers reach their limits. Foreground image: (c) Michael Ventura/ Alamy. Background image: (๑) Immanuel Bloch/MPQ.

\section{NPG LONDON}

The Macmillan Building,

4 Crinan Street, London N19XW

$\mathrm{T}:+442078334000$

F: +442078434563

naturephysics@nature.com

EDITOR

ALISON WRIGHT

INSIGHTEDITOR

ANDREAS TRABESINGER

PRODUCTION EDITOR

JENNY MARSDEN

COPY EDITOR

MELANIE HANVEY

ART EDITOR

ALLEN BEATTIE

EDITORIAL ASSISTANT

AMANDA WYATT

MARKETING

SARAH-JANE BALDOCK

PUBLISHER

RUTH WILSON

EDITOR-IN-CHIEF,

NATURE PUBLICATIONS

PHILIP CAMPBELL

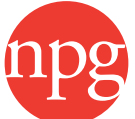

nature publishing group

\section{Quantum simulation}

The competition between the different platforms isn't, however, a 'winner takes all' situation. Each platform has its own advantages and limitations, and different approaches often tackle complementary aspects of quantum simulation. What they have in common is their aim to solve problems that are computationally too demanding to be solved on classical computers, at least at the moment.

Furthermore, the simultaneous development of several platforms for practical quantum simulation offers the intriguing prospect of verifying, once uncharted territory is reached, one simulator using another. In fact, implementing quantum simulations that are too complex for the most powerful classical computers should be already a short-term goal, say Ignacio Cirac and Peter Zoller in their Commentary, and the criteria they set out for a quantum simulator to fulfil might serve as guidelines towards reaching that aim.

We hope that these articles will provide a solid background and historical perspective, together with a broad survey of what has already been achieved. Most of all, we hope that the Insight conveys the excitement of a field that is still young, and inspires further reading and research.

Andreas Trabesinger, Senior Editor point defects.

treas Trabesinger, Senior Editor

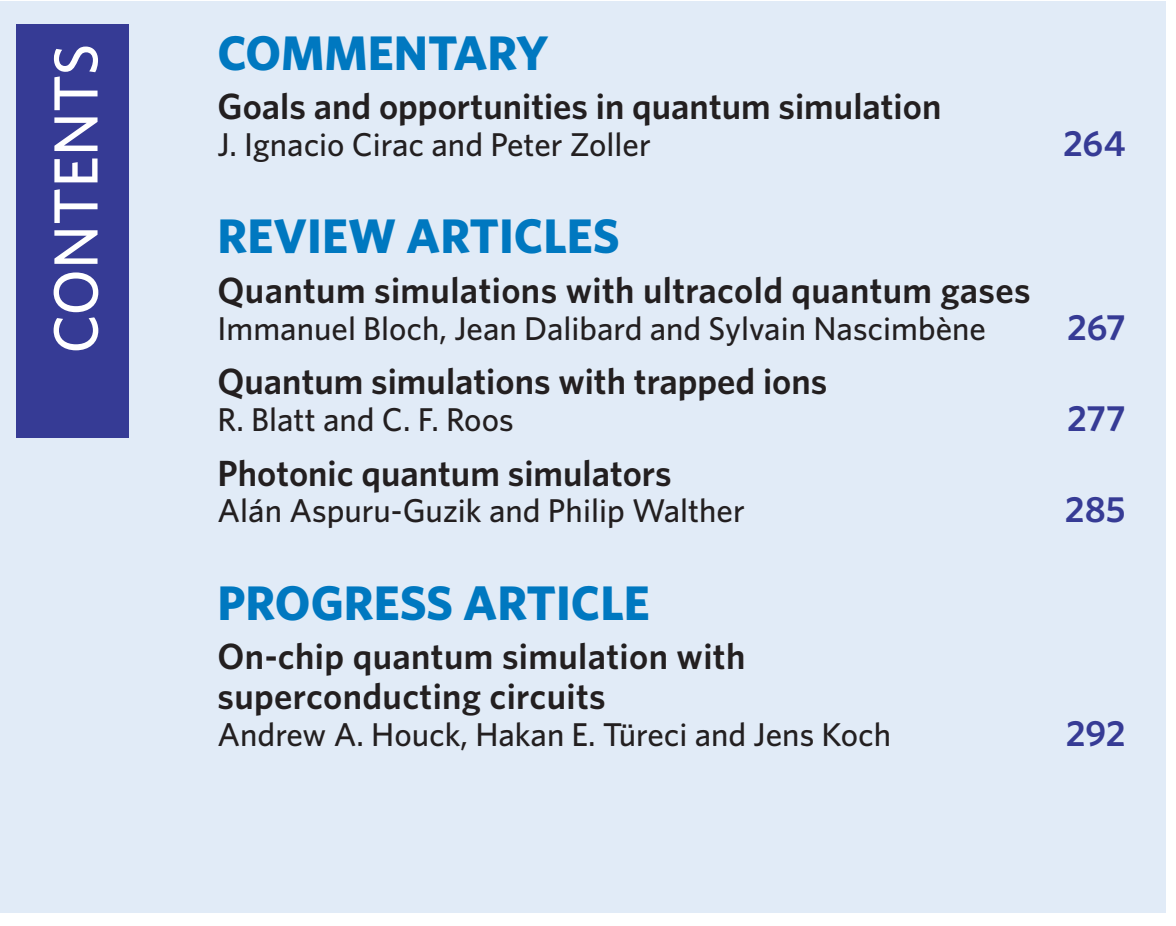

